\title{
Understanding the content pedagogical knowledge among preschool teachers and application of developmentally appropriate practices in teaching
}

\author{
Jain Chee ${ }^{1, *}$, M.N. Mariani ${ }^{1}$, Abdul Jalil Othman ${ }^{1}$, M.R. Nor Mashitah ${ }^{1,2}$ \\ ${ }^{1}$ Faculty of Education, University of Malaya, 50603 Kuala Lumpur, Malaysia \\ 2Department of Early Childhood and Education, Faculty of Education and Human Development, Sultan Idris Education \\ University, Perak, Malaysia
}

\section{ARTICLE INFO}

\section{Article history:}

Received 9 November 2016

Received in revised form

19 January 2017

Accepted 20 January 2017

\section{Keywords:}

Content knowledge

Pedagogical knowledge

Developmentally appropriate practices

Preschool education

\begin{abstract}
A B S T R A C T
The aim of this study is to explore the understanding of the Content Knowledge (CK) and Pedagogical Knowledge (PK) in preschool teachers. CK and PK explored by research participants' understanding of CK and PK and how an understanding of the transformation of knowledge in the preparation and implementation of teaching by applying Developmentally Appropriate Practices (DAP) as proposed by the National Standard Preschool Curriculum (NSPC) of Malaysia. This study is a qualitative case study. Four preschool teachers were selected as research participants. Data were collected through interviews, observations and document analysis, which lasted for six months. Data was analyzed based on suggestions proposed by previous research. Validity and reliability based on triangulation method, pilot study, participant's validation, Cohen Kappa Index Scale and the duration of the study. The findings showed that all research participants were less robust understanding of CK, but good understanding of the PK. Whereas, the application of DAP poorly implemented by the participants These studies raise awareness about the importance of continuous professional training for preschool teachers.
\end{abstract}

(C) 2017 The Authors. Published by IASE. This is an open access article under the CC BY-NC-ND license (http://creativecommons.org/licenses/by-nc-nd/4.0/).

\section{Introduction}

The teacher responsible for the teaching and learning process so that changes in the behavior of children desired effect. To perform the task, preschool teachers need to have knowledge of curriculum for the teaching and learning, early childhood education (Puteh and Ali, 2011), knowledge of pedagogy appropriate to the ages and experience that taught children (Subahan, 1999) and the most important factor in determining the outcome of learning is a strategy that can be used to help children get a meaningful learning. This opinion coincides with the theoretical quality education of Ahlberg (1993), which states qualified teachers, should lead to a meaningful learning.

Therefore, as a teacher, understanding and mastery of the Content Knowledge (CK) and Pedagogical Knowledge (PK) must be held. CK is a

\footnotetext{
* Corresponding Author.

Email Address: jainchee@yahoo.com (J. Chee)

https://doi.org/10.21833/ijaas.2017.03.023

2313-626X/C) 2017 The Authors. Published by IASE.

This is an open access article under the CC BY-NC-ND license

(http://creativecommons.org/licenses/by-nc-nd/4.0/)
}

reference to the field of teacher knowledge about the contents of knowledge or skills or construct a subject, while the PK was associated with knowledge about specific teaching strategies, approaches and teaching techniques. Two constructs specialized knowledge is introduced by Shulman (1986) through Pedagogical Contents Knowledge (PCK). According to Shulman (1986), constructs PCK used to clarify understanding about what teachers make learning fun related to a specific topic or difficult, the conception, pre-conceptions and misconceptions held by students.

Previous studies proved the teacher need to enhance their CK and PK to be effective teachers (Smith, 2010; Clermont et al., 1994; Cochran et al., 1993; Grossman, 1990; Marks, 1990; Shulman, 1987; Doyle, 1986). Teachers master the knowledge of the contents of the curriculum when both elements of procedural knowledge and conceptual knowledge has been acquired, possessed, and be integrated with each other (Hasniza, 2014). The child mastery of the content of learning depends on the proficiency of teachers (Rohaty, 2003) and the strategy of delivering learning content to students (Smith, 2010; Grossman, 1990; Marks, 1990). However, lack of 
knowledge of CK and PK among preschool teacher because they do not dominate procedural knowledge and conceptual knowledge of preschool curriculum.

Whereas, Developmentally Appropriate Practices (DAP) by Bredekamp (1993) has three principles:

1. Consider how a child's development, learning and corresponds to the content and strategies designed for children;

2. Treat children as individuals; and

3. Serve children by identifying changes in the child's ability, confident of the ability of children to be nurtured and given the skills and the children were able to learn.

National Standard Preschool Curriculum (NSPC), published by MOE (2010) proposed to preschool teachers to apply DAP in teaching and learning. The application of the DAP proposed NSPC, begin of the process teaching plans and implementation teaching and learning according to the needs of children with regard to age, personal growth, abilities, talents and interests.

According to the National Association for the Education of Young Children or NAEYC (2009) and Isenberg and Jalongo (2008), characterized by the application of DAP in teaching and learning is like encouraging children to actively explore their environment, can manipulate real objects and learn through it and get hands-on experience. According to NAEYC (2009), the DAP provides opportunities for children to explore, reflect, interact and communicate with children and adults. In addition, pre-school classes as a learning center should provide active learning experiences with real life experience by providing activities such as tours, cooking, doing scientific experiments and participate in community service projects and other activities appropriate to the culture and environment.

\section{Problem statement}

PCK issues, especially those involving CK and PK preschool teachers in Malaysia, has been questioned since the implementation of preschool classes in 1992 as a research by Rohaty (2003), Lim (2007), Puteh and Ali (2011), National Preschool Teaching Report of MOE (2012) by School Inspectorate and Quality Assurance (SIQA), Ministry of Education Malaysia.

According to SIQA (MOE, 2012) found that, preschool teachers' lack of understanding and knowledge of the preschool curriculum content. According SIQA, lack of understanding and knowledge of curriculum content preschool teacher affects an inability to give a clear explanation of any knowledge or skills and are unable to communicate effectively teaching mainly shed light on the knowledge related to concepts or skills are taught, for example learning science and mathematics. The effect of the alleged lack of control of a student's knowledge, skills and values that should be controlled, which puts the mastery of knowledge and skills are at a low level.

The second problem is a lack of understanding and knowledge of the needs and interests of pedagogy in preschool education, as recommended in the preschool curriculum. SIQA reported (MOE, 2012) most preschool teacher's pedagogical practices deviated from their proper use in preschool education especially in teaching and learning.

SIQA (MOE, 2012) reported that some teachercentered teaching and student participation in the learning activities are very limited. Some of the needs and requirements embodied in curriculum such as learning basic modules and thematic modules were not implemented effectively. Therefore, teachers are seen not use teaching approaches and techniques as proposed in the preschool education e.g. 'approach to learning through playing', 'integrated approach', 'thematic approach' and the project approach and so on which the report describes the student-teacher communication is limited.

The teachers understanding on $\mathrm{CK}$ and PK which in line with technique and approach use in teaching and learning process such as DAP. According to Mishra and Koehler (2006) and Shulman (1986), CK and PK constructs used to describe teachers' understanding of what makes learning the skill or titles, easy or hard, about conception, preconceptions and misconceptions that owned by students.

Therefore, teachers should plan and prepare lesson plans and perform teaching by age, selfdevelopment, abilities, talents and interests of children in accordance with the Developmentally Appropriate Practices (DAP) application in teaching and learning, and to achieve the ultimate goal of preschool education and providing children to primary school. However, the report by SIQA (MOE, 2012; 2013) found that teachers do not apply DAP which means, teachers do not plan and prepare lesson plans and perform teaching by age, selfdevelopment, abilities, talents and interests of students.

\section{Research objective}

Overall, this study aims to explore in depth and examine the content of $\mathrm{CK}$ and $\mathrm{PK}$ preschool teachers, as well as how to apply the DAP planning and implementing teaching as proposed by the National Preschool Curriculum Standard (NPCS). In particular, this study aims to achieve the objective would be as follows:

1. To explore content knowledge of preschool teachers

2. To explore pedagogy knowledge of preschool teachers

3. To explore the application Developmentally Appropriate Practices (DAP) in teaching 


\section{Methodology}

This is a qualitative case study design or multiple case studies (Yin, 2003) with four preschool teachers chosen as research participants. The data collected through interviews protocol, teaching observation protocol and document analyzing for six months. The main interview and critical incidents interview was done to inquire the background of the research participants and their knowledge of the National Standard Preschool Curriculum (NSPC) of Malaysia, while pre and post-teaching interviews were held to obtain more information regarding a lesson through teaching observation.

The main interview was held six times, pre and post-teaching interviews held during the teaching processes and the critical incident interviews held once. Meanwhile, teaching observation was held five times. The teaching observation of lesson was done by video recordings and field notes to explored participant's knowledge of teaching preparation and teaching skills in preschool classroom and analysis of the content of the document based on the purpose of the study. Data was analyzed based on Miles and Huberman (1994). Validity and reliability based on triangulation method, pilot study, research participants' validation, Cohen Kappa Index Scale and the duration of the study.

\section{Results}

The results cover the objective of the studies 1,2 and 3. Description of the results based on interviews, teaching observations and document analysis are conducted.

\subsection{Content knowledge of preschool teachers}

All research participants understand the importance of mastering the content available NSPC to implement teaching and learning to prepare pupils for primary education. However, mastering of the content of the NSPC participants was less robust. Research participants were found to have a perspective on the content knowledge of the abstract, conceptual and tend to the direction of school administrators and the District Education Office (DEO) also the demands of parents in the teaching and learning especially in mastering reading skills and math skills of children. Through interviews regarding a model framework concept of the curriculum it was found that research participants do not understand in terms of concept and implementation.

Observation of teaching found the research participants less emphasis on the use of the subject matter content standards and learning standards as contained in national preschool curriculum. The trend study participants to provide skills in reading, writing and arithmetic to children to encourage them to process their subject matter in a form that allows children to master the skills.

\subsection{Pedagogy knowledge of preschool teacher}

The study found that research participants understand the need to use certain techniques and approaches proposed in the implementation of teaching and learning. Research participants also learn how to approach to help children understand what is to be served. However, research participants do not practically use approaches and teaching techniques as suggested in preschool classes. Overally, the research participants do not take the time management and control of the classroom in teaching and learning. The data were collected, found the research participants' understanding of content knowledge is good less practice in approach as proposed.

\subsection{Application of DAP by preschool teachers}

Developmentally Appropriate Practices (DAP) recommended in NSPC is the ultimate goal of providing preschool children to elementary school. The research participants also understand the importance and necessity of DAP application of teaching and learning in preschool classes as suggested of NSPC. Although nonetheless features the application of which emphasizes the use of teaching and learning methods appropriate to the age, personal growth, abilities, talents and interests of children cannot be seen during the implementation of the teaching and learning process conducted by the research participants. Participants have specific responses. The responses were negative to the application of DAP in the implementation of teaching and learning in preschool class. Research participants considered the application of DAP difficult to implement because the children have a variety of ages, various selfdevelopment, multi-talented, multi-talents and interests. In addition, participants and other preschool teachers involved in the implementation of the NADI program conducted by the DEO, the program is to help students master the skills of reading and mathematics skills. In particular, all of the data obtained through data collection methods described, characterized by the application of DAP in the implementation of teaching and learning by the participants in this study poorly implemented as proposed by national preschool curriculum.

\section{Discussion}

The discussion of understanding of content knowledge, pedagogical knowledge and Application Developmentally Appropriate Practices in teaching by research participants described by research objective 1,2 and 3 .

\subsection{Understanding of content knowledge}

Overall, study found, research participants lack of understanding of content knowledge. Even so, the 
participants are aware of the importance and the need to own and control their understanding and knowledge of the CK. Lack of understanding and knowledge of the CK can be viewed during interviews carried out and when the participants expressed their subject matter to children.

The study also found that the results of the teaching and learning of all the participants focused on cognitive aspects and not in line with the wishes contained in NSPC of providing primary school pupils and at the same time create a better balance in terms of physical, emotional, spiritual and character. This finding is somewhat at odds with Siti (2012) and Anderson and Pavan (1998) who said that the formation of identity students should be the primary goal of education in schools, especially for younger generations should be balanced in terms of intellect and personality to improve human relations.

Based on the findings of this study, all participants were found to be fully refer to NSPC when designing learning focus instead, it depends on the situation and the demands of parents, school administrators and program organized by DEO. The findings show that all drill activities and memorized, refer to the actions taken by all participants to ensure that children master reading and math that the demands of parents, school administrators, and DEO.

Lack of content knowledge of research participants, there by exhibiting the inability of teachers to give proper explanation on aspects of learning and skills taught. Participants by giving inaccurate answers related to aspects of learning or skills taught when asked by children. According to Ives (2009) and Leinhardt et al. (1990), the answer is quite right that the teacher whether right or wrong will be remembered by children. This demonstrates the power and effectiveness of the answers given by the participants to the children, especially for children who are capable of low (Hasniza, 2014; Rozaiman et al., 2016; Leinhardt et al., 1990). These findings support the study by Siti (2012) and Smith (2010) found that teachers who have an understanding and less knowledge on content, concepts in the curriculum or the subject matter is a subject will have problem for the teaching of these subjects.

\subsection{Understanding of pedagogical knowledge}

All participants understand the importance and necessity of teaching and learning approaches that are consistent with preschool education. Through the observations found the approach used by the participants tends to teacher-centered teaching approaches and teaching methods give orders. The approach adopted by the participants mainly to memorize the alphabet or numbers. The teaching approach is used as drill and memorizing mean the process of remembering the alphabet, syllables, numbers and mathematical symbols to enable children to master in reading skills and math operations.

The study also found, all participants use a variety of teaching and learning techniques such as lighting, direction, debating, assignments, acting and simulation. However, there are several techniques used but does not involve activities in an interactive teaching and learning rather than teacher-centered. The results showed debating techniques, acting and simulation dominated by the teacher and less questions that require children to express their feelings and actions.

This situation shows the techniques used proposal by Hasniza (2014) and Kreber and Cranton (2000) which explains the need for some special techniques to teach a subject, knowing when and how to get meaningful feedback and rate the quality of the specific techniques used in teaching in order to draw lessons how the planning and implementation of teaching based on age, personal growth, talent, abilities and interests of children who can help children think critically, at the same time can provide all primary school pupils and produce a balanced as envisaged in NSPC.

This study also showed that all participants use basic teaching tools such as activity books, instructional charts and whiteboards. No difference was shown by participants whether participants majoring in pre-school education and nonspecialized preschool. The situation is somewhat at odds with Hasniza (2014) who found that teachers are not specialized teaching preschool too shackled by the text or the like. In fact, this study shows, the participants have also used specialized preschool books for the teaching activities.

The study also showed that all participants were very motivated and they encouraged the children to study hard and be more active during learning outside the classroom such as gardening and planting flowers. This situation can be seen especially when debating activities, in which participants gave affirmation and praise. Such a situation is as envisaged in national preschool curriculum.

The findings of this study showed equal part of the definition of classroom management by Siti (2012) and Kreber and Cranton (2000) which should include knowledge on how to motivate students, to teach to attract, motivate cooperation among students, helping students overcome learning difficulties, help students think critically and how to get meaningful feedback.

Overally, the findings of pedagogical knowledge indicate that all participants have a good knowledge of pedagogy, the method and style of teaching and learning. Even supplied sources of the same curriculum which is an indication national preschool curriculum and their understanding of approaches and techniques that are suggested, but teaching approaches and techniques that have been set aside and are affected by planning and teaching and learning practices to meet the demands of parents, school administrators and DEO program. 


\subsection{Application of DAP in teaching}

The study found that the application of teaching and learning DAP e.g. age-appropriate, selfdevelopment, abilities, talents and interests of children are not applicable during implementation of teaching and learning by the participants in preschool classes.

Interviews were conducted, participants were unable to explain briefly or depth on DAP in preschool education even though they are aware of the needs and interests of such application. So it is with the lesson plan provided by participants who do not declare the DAP once participants cannot be considered to apply DAP carried out during teaching and learning. This finding matched by SIQA Report (MOE, 2012; 2013), which states that teachers do not apply DAP in teaching and learning, which means that teachers do not plan and provide teaching lesson plan and implement age-based, selfdevelopment, abilities, talents, interest's children and approaches that are appropriate to preschool education.

The study also found that the knowledge and skills of the participants on the philosophy that less DAP cause them to neglect other learning domain, which is also important in assisting the development of children. For example, the domain of physical, emotional, social and cognitive development in connection with which this development is related to each other. These findings are as reported in the SIQA (MOE, 2012; 2013), about teaching in a preschool class.

\section{Conclusion and recommendations}

This research hopes to bring awareness to teachers about the importance of teaching and learning in the mold of preschool education to nurture the children to continue to learn. Therefore, teachers need to have understanding of CK and PK because the two constructs are the key for preschool education and teachers' professional knowledge. These requirements enable preschool teachers apply a variety of teaching and learning approaches such as application-based DAP. Teachers need to show determination to learn new teaching practices and be willing to accept changes in the curriculum that have been enacted. It is considered as the curriculum, teachers need to be concerned about the objectives of the curriculum are designed to enable the government to achieve. Collaboration between schools, PTA, DEO, Department of State and Ministry of Education Malaysia is an important element and should be established for each party played a major role in contributing to the development of preschool education, especially from the aspect of implementation of the curriculum in preschool. The programs to be implemented in school classes should be in line with the requirements of preschool education and curriculum, otherwise it feared would disrupt the implementation of learning in preschool class. DEO, Department of State and Ministry of
Education Malaysia must create a training to share their expertise and experience as a result of this study found that study participants who took part in the study were given formal training only once, the effect of CK and PK participants found to be low, this gives space to study participants for not applying the appropriate teaching approach for students and preschool education, such as the application of DAP in teaching and learning.

Each party of course has their expertise in dealing with specific issues. A method to ensure that a business that is achieved is to involve individuals who actually specialize in solving the issues to be addressed (Puteh and Ali, 2011; Fullan, 2007). Efforts such as these give space to all parties discuss issues, particularly in terms of teachers' professional knowledge as content knowledge, pedagogical knowledge and use of curriculum appropriate to a child's development. Activities such partnership is a positive step that a reasonable and able to bring change to the preschool educational excellence.

\section{References}

Ahlberg M (1993). Concept maps, Vee diagrams and Rhetorical Argumentation (RA) Analysis: Three educational theorybased tools to facilitate meaningful learning. In the $3^{\text {rd }}$ international seminar on misconceptions and educational strategies in science and mathematics. Cornell University, Ithaca, New York: 1-5.

Anderson RH and Pavan BN (1998). Nongradedness: Helping it to happen. Technomic Publishing, Pennsylvania, USA.

Bredekamp S (1993). The relationship between early childhood education and early childhood special education: Healthy marriage or family feud?. Topics in Early Childhood Special Education, 13(3): 258-273.

Clermont C, Borko H and Krajcik J (1994). Comparative study of the pedagogical content knowledge of experienced and novice chemical demonstrators. Journal of Research in Science Teaching, 31(4): 419-441.

Cochran KF, DeRuiter JA, and King RA (1993). Pedagogical content knowing: An intergrative model for teacher preparation. Journal of Teacher Education, 44(4): 263-272.

Doyle W (1986). Content representations in teacher's definitions of academic work. Journal of Curriculum Studies, 18(4): 365379.

Fullan M (2007). The new meaning of educational change. Teachers College Press, New York, USA.

Grossman PL (1990). The making of a teacher: Teacher knowledge and teacher education. Teachers College Press, New York, USA.

Hasniza N (2014). Pre-service teachers' TPACK and experience of ICT integration in schools in Malaysia and New Zealand. Ph.D. Dissertation, University of Canterbury, New Zealand.

Isenberg JP and Jalongo MR (2008). Exploring your role: An introduction to early childhood education. Prentice Hall, New Jersey, USA.

Ives SE (2009). Learning to teach probability relationship among preservice teachers' beliefs and orientations, content knowledge, and pedagogical content knowledge probability. Ph.D. Dissertation, North Carolina State University, USA.

Kreber C and Cranton PA (2000). Exploring the scholarship of teaching. The Journal of Higher Education, 7(14): 476-495. 
Leinhardt G, Zaslavsky O, and Stein MK (1990). Functions, graphs, and graphing: Tasks, learning, and teaching. Review of Educational Research, 60(1): 1-64.

Lim CP (2007). Effective integration of ICT in Singapore schools: Pedagogical and policy implications. Educational Technology Research and Development, 55(1): 83-116.

Marks R (1990). Pedagogical content knowledge: From a mathematical case to a modified conception. Journal of Teacher Education, 4(3): 3-11.

Miles HB and Huberman AM (1994). Qualitative data analysis: An expanded sourcebook. SAGE Publications, California, USA.

Mishra P and Koehler MJ (2006). Technological pedagogical content knowledge: A framework for teacher knowledge. Teachers College Record, 108(6): 1017-1054.

MOE (2010). National standard preschool curriculum. Department of Curriculum Developing. Ministry of Education, Kula Lumpur, Malaysia.

MOE (2012). School inspectorate and quality assurance (SIQA) of national preschool teaching report. Ministry of Education, Kula Lumpur, Malaysia.

MOE (2013). School inspectorate and quality assurance (SIQA) of national preschool teaching report. Ministry of Education, Kula Lumpur, Malaysia.

NAEYC (2009). Developmentally appropriate practice in early childhood programs serving children from birth through age 8. National Association for the Education of Young Children. Available online at: http://www.naeyc.org

Puteh SN and Ali A (2011). Pendekatan bermain dalam pengajaran bahasa dan literasi bagi pendidikan prasekolah [The Play
Approach In Teaching Language And Literacy For Preschool Education]. Jurnal Pendidikan Bahasa Melayu [Malay Language Journal Education (MyLEJ)], 1(2): 1-15.

Rohaty MM (2003). Pendidikan prasekolah: Cabaran Kualiti (Syarahan Perdana). Universiti Kebangsaan Malaysia Press, Selangor, Malaysia.

Rozaiman M, Zamri M, Noor IMT, and Haron AR (2016). Pengetahuan teknologikal pedagogikal kandungan kesusasteraan melayu: peranan guru sastera dalam SPN 21 [Technological pedagogical content knowledge in Malay literature: The roles of Malay literature teachers in SPN 21]. Jurnal Pendidikan Bahasa Melayu [Malay Language Journal Education], 1(2): 85-98.

Shulman LS (1986). Those who understand teach: Knowledge growth in teaching. Educational Researcher, 15(2): 4-14.

Shulman LS (1987). Knowledge and teaching: Foundations of the new reform. Harvard Educational Review, 57(1): 1-22.

Siti HN (2012). Kajian kes terhadap amalan pengetahuan teknologi pedagogi dan kandungan (PTPK) guru fizik Johor Bahru. Ph.D. Dissertation, Universiti Teknologi Malaysia, Johor, Malaysia.

Smith C (2010). Mathematics in early childhood: An investigation of mathematics skill in preschool and kindergarten students. Ph.D. Thesis, Alfred University, New York, USA.

Subahan TMM (1999). Penggunaan peta konsep dan pencapaian matematik [The use of concept mapping and mathematics achievement]. Jurnal Kurikulum, 1(2): 1-32.

Yin RK (2003). Case study research: Design and methods. SAGE Publications, California, USA. 